\title{
Assessment of suicide risk factors among attempted suicide in Ardabil
}

\author{
Parviz Molavi*, Mansoureh Karimollahi, V Abbasi-Ranjbar and \\ H Mohamadnia
}

Address: Ardabil Medical Sciences University, Ardabil, Iran

* Corresponding author

\author{
from International Society on Brain and Behaviour: 3rd International Congress on Brain and Behaviour \\ Thessaloniki, Greece. 28 November - 2 December 2007 \\ Published: 17 April 2008 \\ Annals of General Psychiatry 2008, 7(SuppI I):S320 doi:I0.I 186/I744-859X-7-SI-S320
}

This abstract is available from: http://www.annals-general-psychiatry.com/content/7/SI/S320

(c) 2008 Molavi et al.; licensee BioMed Central Ltd.

\section{Background}

Suicide is defined as finishing life deliberately upon conditions that done by individual's own desire and own hand. Suicide is a major problem in social health and its rate is now increasing among individuals at 15-24 age range. This study has performed to detect risk factors and major fundamental agent been used in suicide.

\section{Materials and methods}

This is a descriptive cross-sectional study. Statistical unit in this study obtained from individuals that committed suicide and hospitalized in fatemi and Buali hospitals of Ardabil. Sample quantity was 218 cases that have been from both sexes and all ages. Clinical interviews have derived from patients and their first-degree relatives and appropriate tests of MMPI were done. The results have been analyzed with descriptive statistics of SPSS software.

\section{Results}

In this study, the most cases of committing suicide were within 15-25 age spans, with the following group profile. female $(61 \%)$, married $(53.22 \%)$, educated individuals with high school and diploma $(35.76 \%)$, and middle class socio economic status(57.34\%). 61.47\%of these individuals were afflicted by psychological disorders with 58.72 percent were afflicted with personality disorders. The most used method for suicide was taking drugs and toxins $(90.83 \%)$. Conflict with spouse has been found as most cause of suicide.

\section{Conclusions}

This study revealing that the prevalence of different risk factors that play a role in committing suicide are as follows: low level of education, end of adolescence and beginning of youth, female sex, being married, family problems specially among new married couples, psychiatric and personality disorders and easy access to drugs and toxins. 